\title{
OBSERVATIONS ON THE FORMATION AND GROWTH OF TUBERS ON THE POTATO PLANT ${ }^{1}{ }^{2}$ )
}

\author{
N. KRIJTHE \\ Institute for Potato Storage, Wageningen
}

\section{INTRODUCTION}

In spite of the extensive research carried out on potatoes, comparatively little attention has so far been paid to the growth of potato tubers from the moment at which they first form to the time at which they are harvested. The most detailed investigations in this sphere have been performed in America (Clark, 1921; SмIтн, 1938), while consideration is being given to this aspect of potato study in Germany as well.

The immediate cause of the investigation described in the following pages was the question of the connection between the preliminary germination (chitting) method, the number of sprouts on the seed potato, and grading after harvesting. There are, however, other problems in the sphere of potato research, in solving which exact study of the growth of the tuber can be of assistance. The present investigation will be continued for a number of years; in the future the programme will include working with a larger number of potato varieties than have been used up till now, whilst the conditions under which the plants grow will also be varied, as hitherto only potatoes from moisture-holding sandy soil have been concerned in the tests.

\section{METHOD OF WORKING}

The investigation was carried out in various years, with some varieties the seed potatoes of which had either been chitted in different ways (1953), were of different sizes (1954), or had been stored in the winter under differing conditions and had then been chitted in different ways (1955). This procedure was followed with the object of studying the influence of such treatment on the growth of tubers.

All varieties, and all potatoes of one variety, which had been subjected to differing treatments, were planted out in the field in moisture-containing sandy soil, on the same date each year. Ten plants were lifted from each individual object of treatment fourteen days after planting; thereafter, lifting took place every week, as a rule. After lifting, the plants were carefully studied - in 1953 and 1954 they were all described in detail, in 1955 this was only done in respect of the plants lifted first. Particular attention was paid to the development of the stolons, their place on the stems, and the locations of the largest and smallest tubers on the plant. The measure of size adopted for the tubers was their length, as that proved to be most suitable for the type of work concerned.

1) Received for publication September 5, 1955.

2) Lecture given during the Informal Potato Conference, held 8-10 August, 1955, at Wageningen. 
The SEED POTATOES USED AND THEIR TREATMENT

1953 varieties : size of seed potato:

Bintje, Eigenheimer, Voran; treatments :

$35 / 40 \mathrm{~mm}^{3}$ );

1 storage in winter at $2^{\circ} \mathrm{C}$, chitting at $20^{\circ} \mathrm{C}$, this treatment was called "rapid chitting" 4 ).

2 storage in winter at $2^{\circ} \mathrm{C}$, chitting at gradually increasing temperatures, $5^{\circ}-7^{\circ}-9^{\circ} \mathrm{C}$; this treatment was called "gradual chitting".

1954 varieties : Bintje, Voran ;

size of seed potatoes : $35 / 40 \mathrm{~mm}^{3}$ ), graded in 3 sizes : "large", "medium" and "small";

treatment :

1955 varieties : storage in winter at $2^{\circ} \mathrm{C}$, chitting at $20^{\circ} \mathrm{C}$. Eersteling, Bintje, Eigenheimer, Meerlander, Ysselster;

size of seed potatoes : $35 / 40 \mathrm{~mm}^{3}$ );

treatment :

1 storage in winter in a glass seed potato storehouse ;

2 storage in winter at $2^{\circ} \mathrm{C}$, chitting at $9^{\circ} \mathrm{C}$;

3 storage in winter at $2^{\circ} \mathrm{C}$, chitting at $20^{\circ} \mathrm{C}^{4}$ );

4 storage in winter under through-cooling conditions, chitting at $9^{\circ} \mathrm{C}$;

5 storage in winter under through-cooling conditions, chitting at $20^{\circ} \mathrm{C}^{4}$ ).

\section{RESUltS OF THE INVESTIGATION}

On examining the complete plants after each lifting, it was found that the place on the plant at which the largest tubers grow is always approximately the same in all plants. This proved also to be the case with the medium-sized and small tubers. Although the various potato varieties exhibit differences as regards number and ramification of stems, and length, number and ramification of stolons, there is nevertheless a high degree of conformity in the location of the large, medium-sized and small tubers on the plants. It is therefore possible to give the general, schematic view of a potato plant shown in Fig. 1. For a detailed description of a potato plant the reader is referred to a previous publication (KRIJTHE, 1946).

A seed potato develops a sprout (Fig. 1 A); this is a compact stem with small leaves and small buds in the axils of the leaves. After the seed potato has been planted, the sprout expands and the buds in the axils of the small leaves begin to develop (Fig. 1 B). These developing buds may grow into

3) This grading was determined in the usual way, i.e. as is also customary in grading potatees for commercial use.

4) The sprouts of the seed potatoes used in all treatments were of the same length at the moment of planting. This means that the period of chitting at $9^{\circ} \mathrm{C}$ was longer than at $20^{\circ} \mathrm{C}$. 
stolons (Fig. 1 C-4) or stems, which emerge from the ground and become haulms bearing leaves (Fig. 1 C-3). The stolons and the underground parts of these haulms bear in their turn small (rudimentary) leaves with buds in the axils (Fig. $1 \mathrm{~B}$ ), and these buds can develop into stolons of the second order (Fig. 1 C-5).

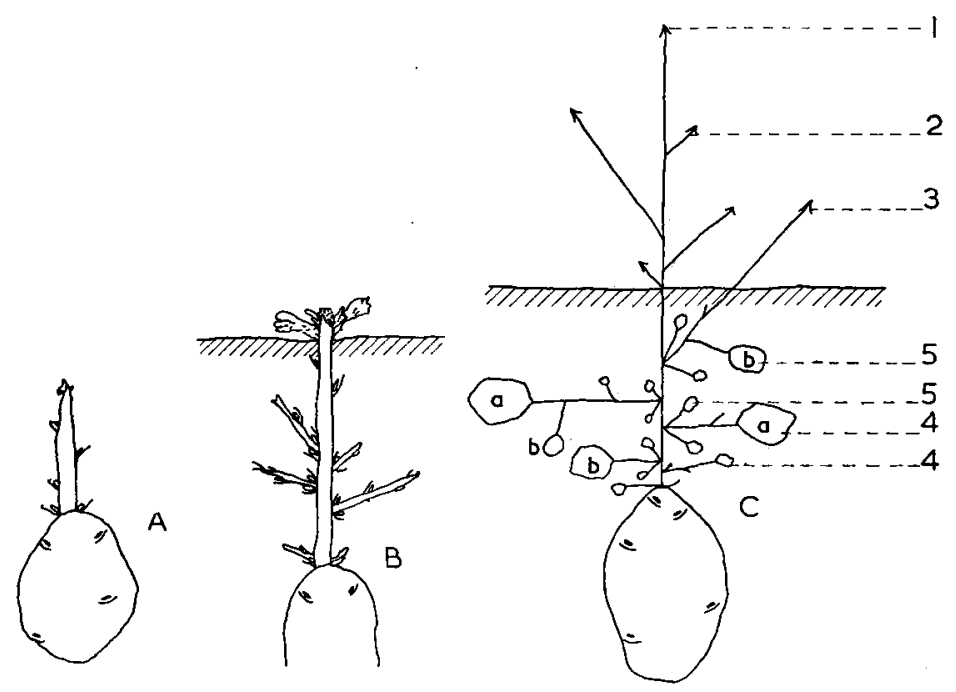

Fig. 1. A. Tuber with sprout.

B. Situation after planting; the stem just emerges from the soil.

C. Situation during the period of tubehformation.

1. mainstem, the stem that develops directly from the seed-tuber.

2. overground branchstem; a stem with leaves developing from the overground part of the mainstem.

3. underground branchstem; a stem with leaves developing from the underground part of the mainstem.

4. stolon of the first order developing from the mainstem.

5. stolon of the second order (branchstolon) developing either from a branchstem or from a stolon of the first order.

ThE LOCATION OF THE TUBERS

A tuber can develop at the tip of every stolon.

The largest tubers are not found on the stolons close to the base of the sprouts, but on the stolons which occupy the third, fourth or fifth place from the base of the sprouts (Fig. $1 \mathrm{C}-\mathrm{a}$ ).

The medium-sized tubers are found:

1 on stolons of the first order, more or less distant from the base of the sprouts ;

2 on stolons of the second order which have developed from stolons bearing the largest tubers;

3 on stolons of the second order which have developed from an underground branch stem.

These three types of medium-sized tubers are shown in Fig. $1 \mathrm{C}-\mathrm{b}$.

The smallest tubers are located on the other stolons - in general on secondary stolons and on stolons of the first order which are unfavourably situated. 
Before we go on to discuss the results of measuring the tubers harvested on the various lifting dates, attention should be drawn to the following generai tendencies :

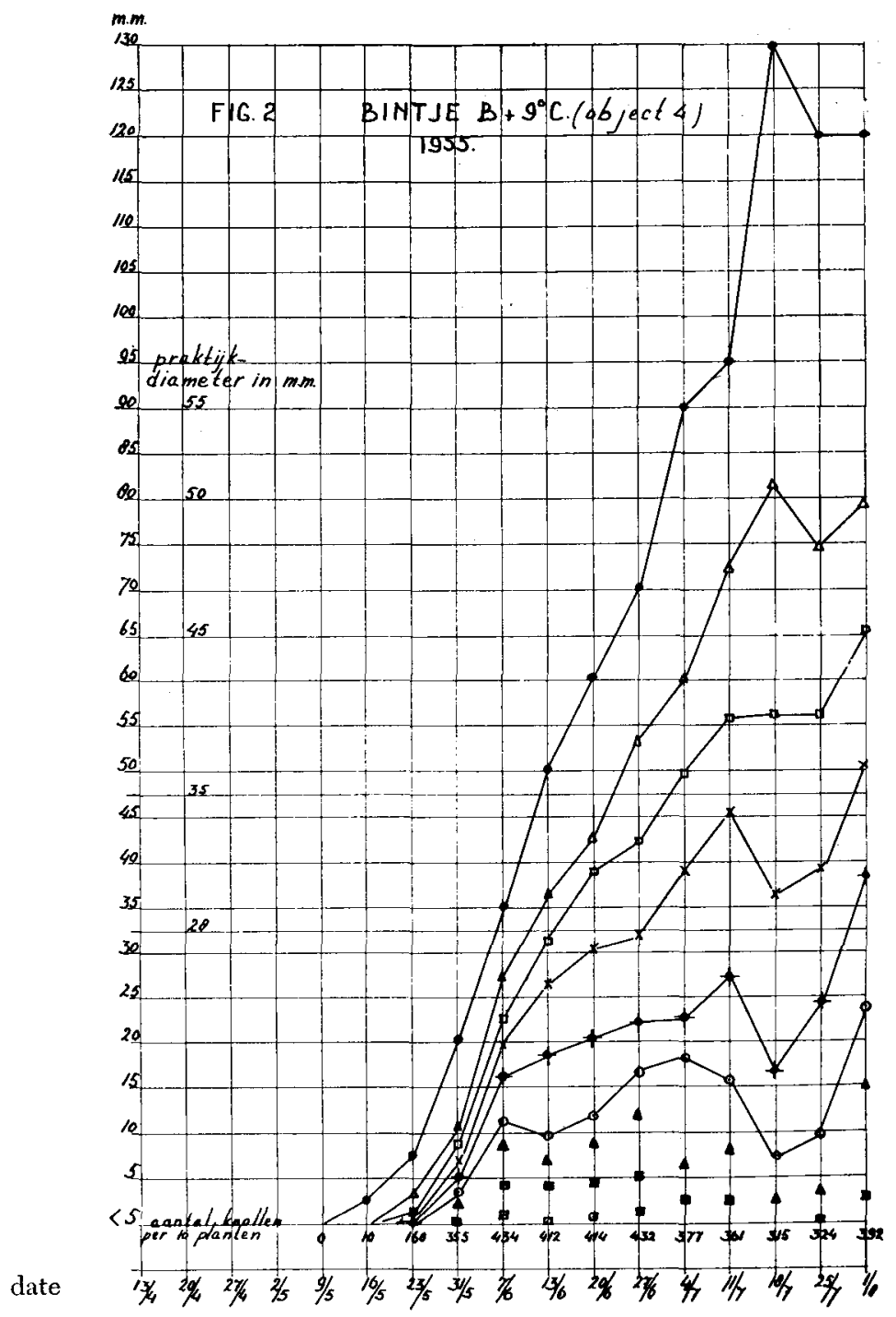

FIG. 2. BinTJE 1955 (treatment 4 )

praktijkdiameter in $\mathrm{mm}=$ diameter according to commercial grading, aantal knollen per 10 planten $=$ number of tubers per 10 plants.

1 It appears that a large tuber at the tip of a stolon attracts to itself a stream of nutriment which, at the same time, causes better development of the tubers on stolons of the second order in the vicinity of the large tuber.

2 If a plant possesses various haulms the large tubers will be found growing on each of these haulms. Thus, in the case of the ten largest tubers of a plant with five stems, two of the tubers will be located on each haulm 

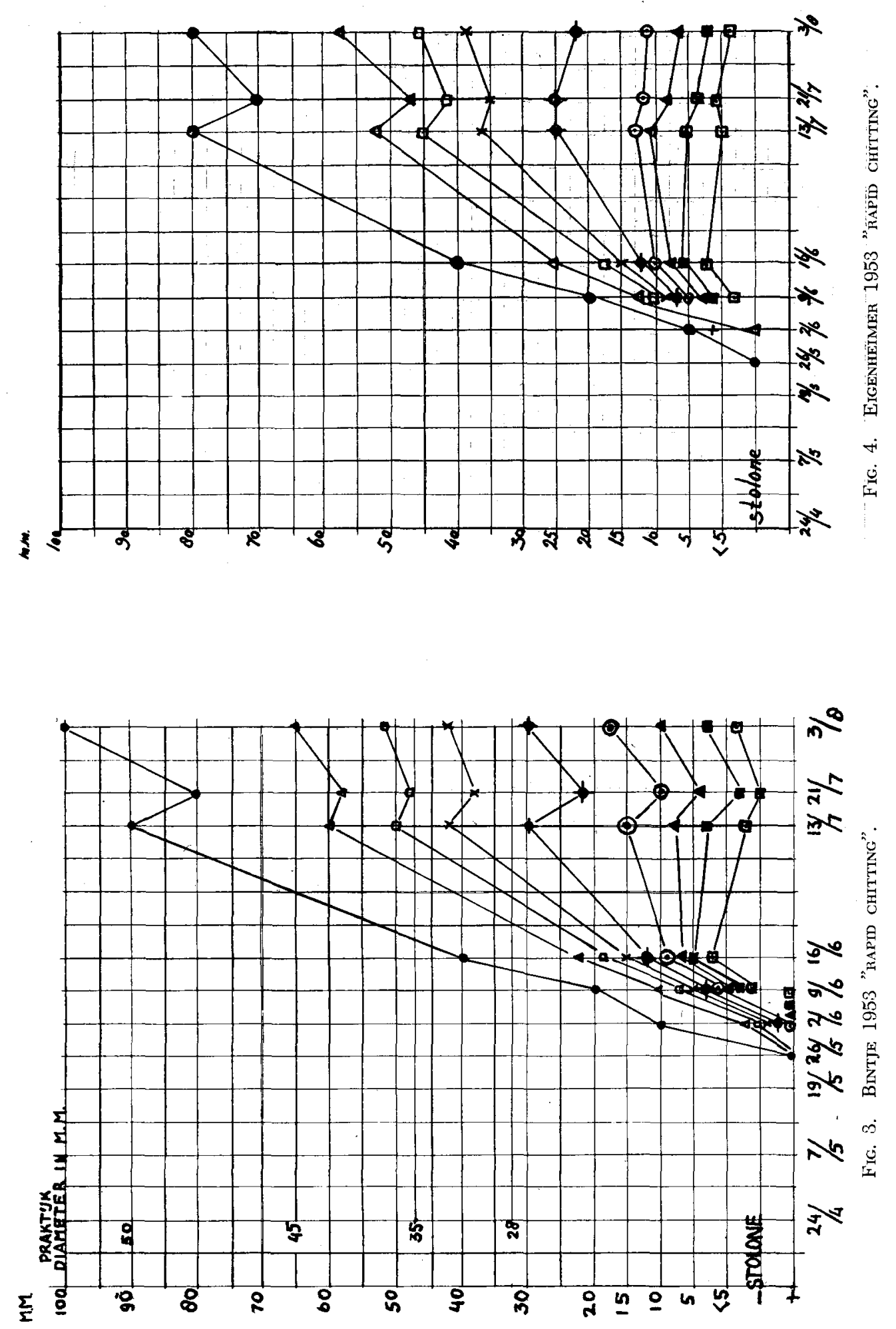

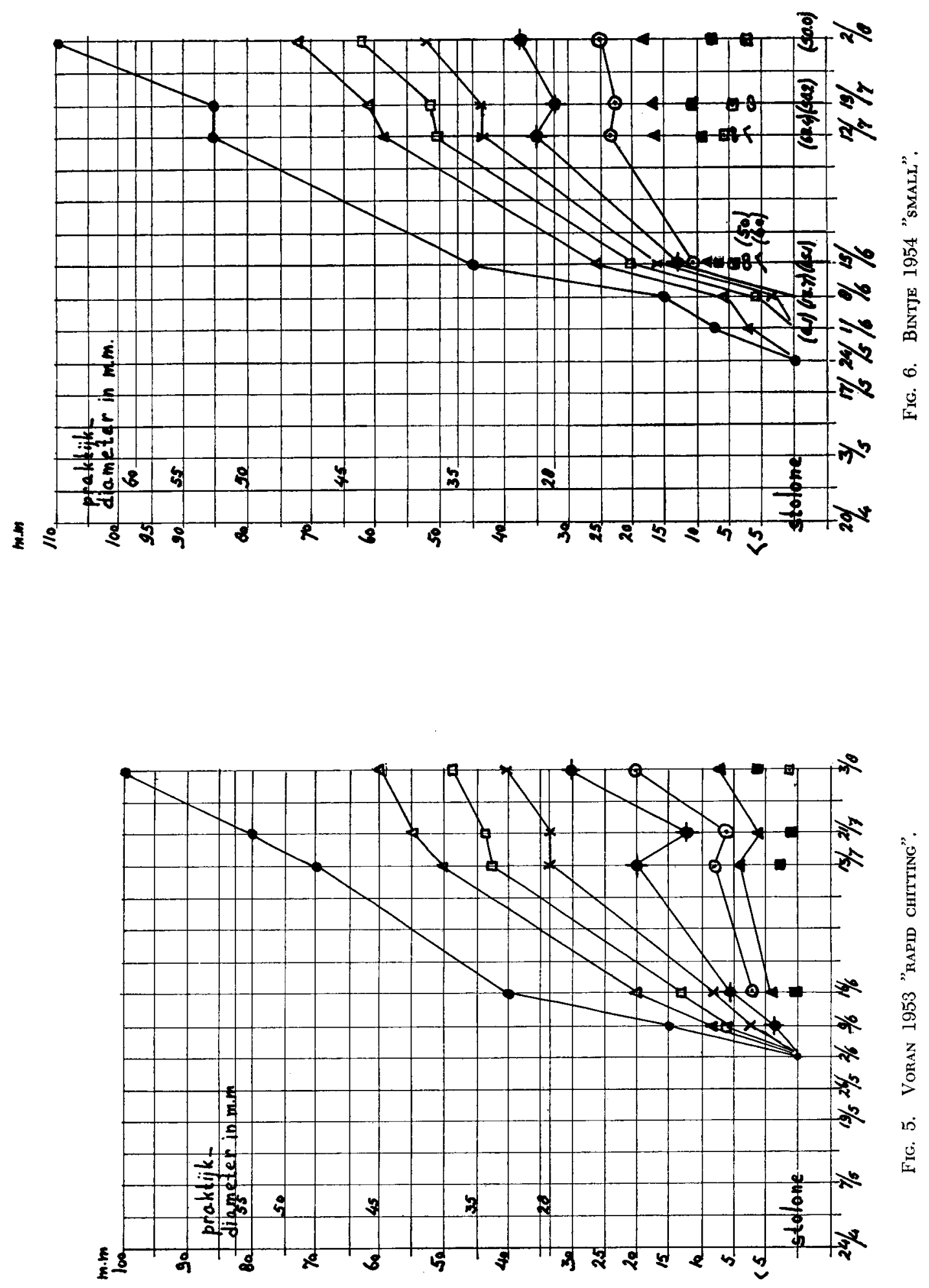

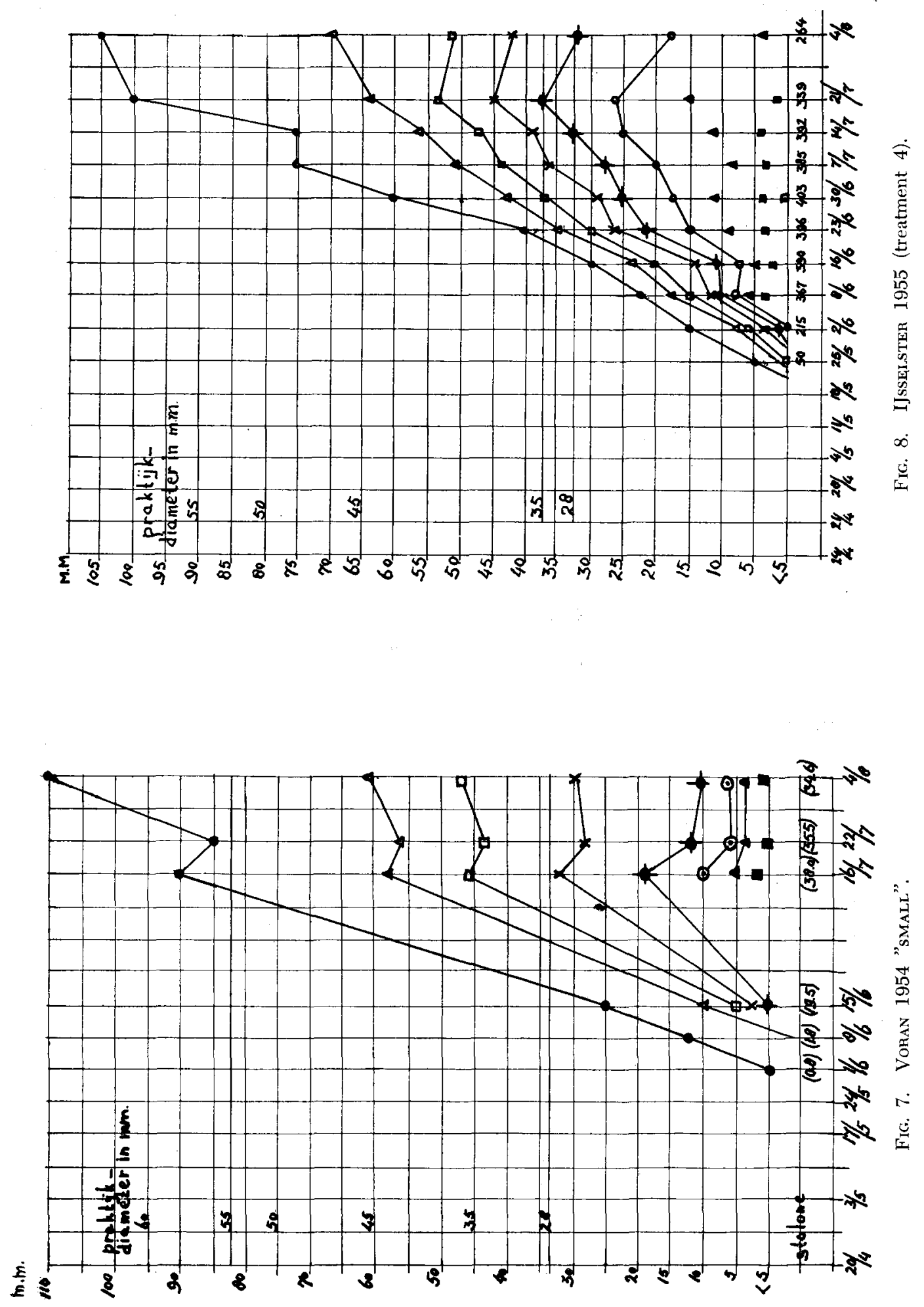
This, at any rate, is the rule: an explanation can always be found for any departures ; for instance, if one of the five haulms has remained underdeveloped, it is hardly likely to bear two of the plant's largest tubers.

\section{FORMATION AND GROWTH OF TUBERS}

In Fig. 2, the results of measurement of the harvested tubers are shown in graph form in respect of Bintje 1955, treatment 4 . On the abscissa the interval of time between planting and lifting has been plotted - viz. two weeks, four weeks, five weeks, etc. On the ordinate, the length in $\mathrm{mm}$ of the tubers harvested has been plotted.

The figures $0,10,160 \ldots 392$ give the total number of tubers present per lifting of ten plants. The tubers have been allocated to various size classes.

- Length of the largest tuber from ten harvested plants.

$\Delta$ Average length of the "fourth tuber" from ten plants, i.e., average length of the fourth largest tuber from each plant.

$\square$ Average length of the 8th tuber from ten plants, calculated as above.

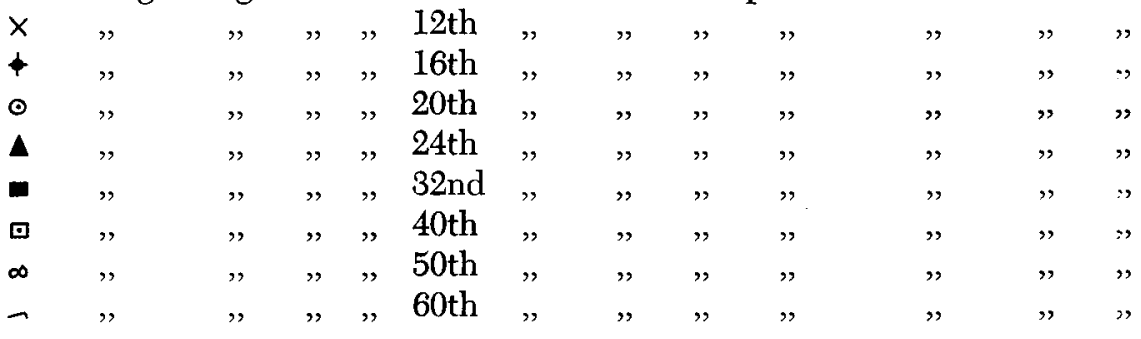

By connecting the corresponding symbols on the various lifting dates lines are obtained which represent the growth of the tubers of the various length classes.

In Figs. 3 to 8 the results of measuring the harvested tubers in 1953, 1954, and 1955 have been plotted in the same way in respect of some treatments of various varieties.

For the purpose of compiling these graphs, it has been assumed that the largest tuber remains the largest from the moment of formation until harvest, and that the same is true of the other tuber sizes, i.e. the smallest remains the smallest, etc. As has already been stated, the largest tubers at each lifting are always found in the same position on the plant. This fact renders the truth of our assumption probable.

The following conclusions can be drawn from the graphs:

I Initial development of tubers (tuber formation) is generally complete within two or three weeks. This conclusion has been based on the fact exemplified, for instance, in Fig. 2, in which the number of tubers present on 7 June is never exceeded later, and in which all size classes of tuber are seen to be represented on this date (see the various symbols in the graph).

II The lines diverge, which means that the largest tubers grow most quickly: the smaller the tubers, the slower they grow. The tubers which come twentieth or twentyfourth in order of size, or even lower, do not grow 
at all after formation, and sometimes disappear before lifting takes place in August.

III Many tubers are formed, but only about half the total number develop to a size which is of economic importance. On counting it was found that not more than 16 to 20 out of a total of 35 to 50 tubers formed, grow to sufficient size.

As regards the first conclusion, the following may be said. The period of tuber formation begins five or six weeks after planting. Figs. 9 and 10 show

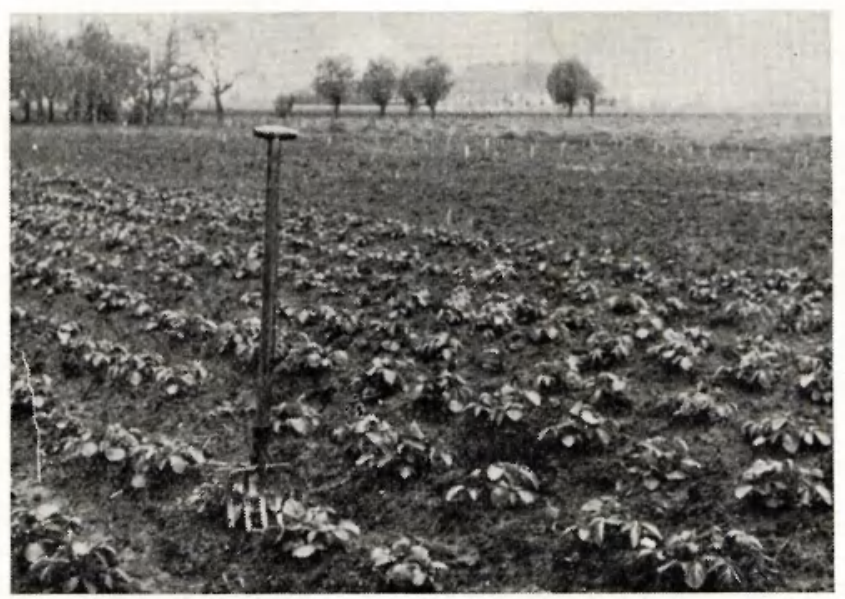

Fis. 9. BintJe 1955 in the field) ON 24ti Max, siX Weers after planting.

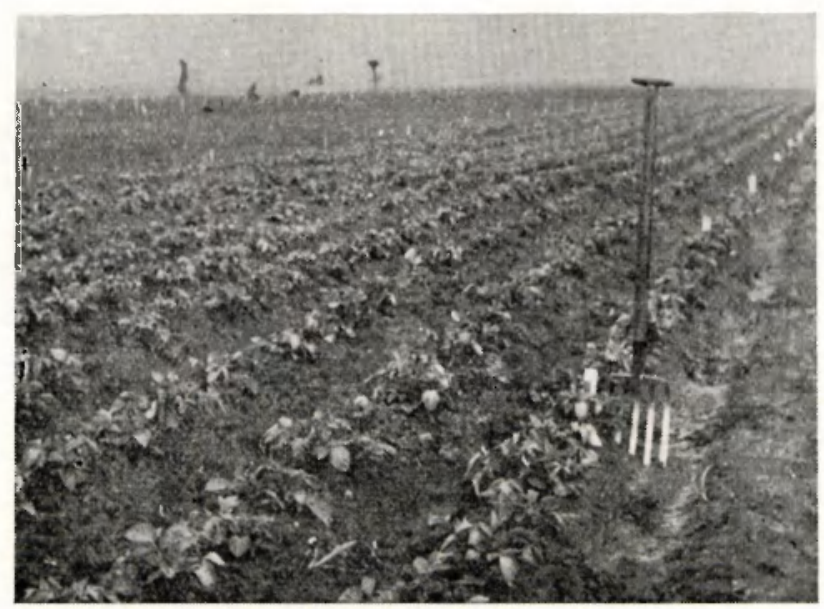

Fig. 10. Eersteling 1955 in the Field on 24Th May, Six weeks after planting.

Bintje 1955 and Eersteling 1955, respectively, in the field at the beginning of the tuber formation period.

A number of plants which were lifted on 24th May are shown in Figs. 11 and 12 . 
In 1955 the average number of tubers per plant in the case of Bintje was found to be 39 .

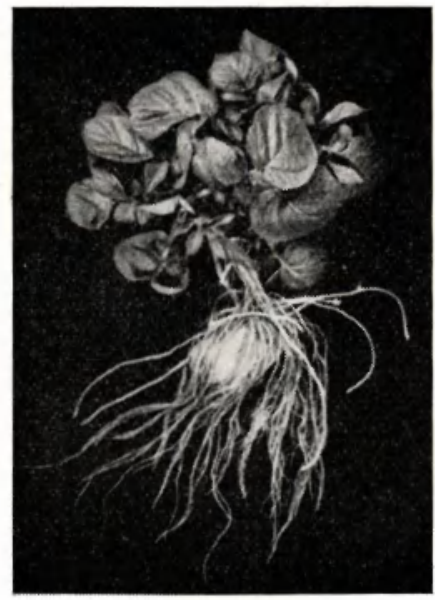

Fig. 11. BintJe 1955, Lifted on 24th May. This PLANT haD 16 TUBERS, THE LARGEST OF WHICH WAS 8 MM LONG.

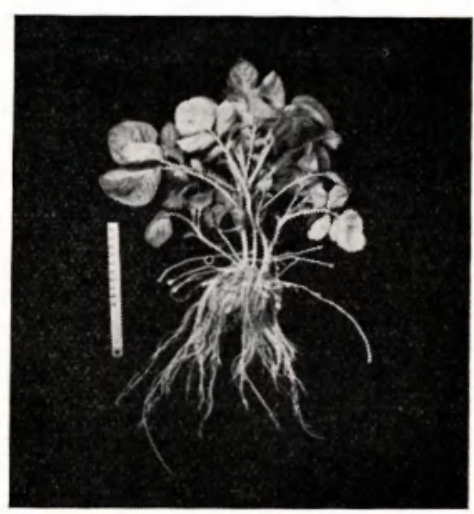

Fig. 12. Eensteling 1955, LifTed on 24TH May. This Plant had 47 tubers, THE LARGEST OF WHICH WAS 10 MM LONG.

The Figs. 13 and 14 show Bintje one, respectively two weeks later.

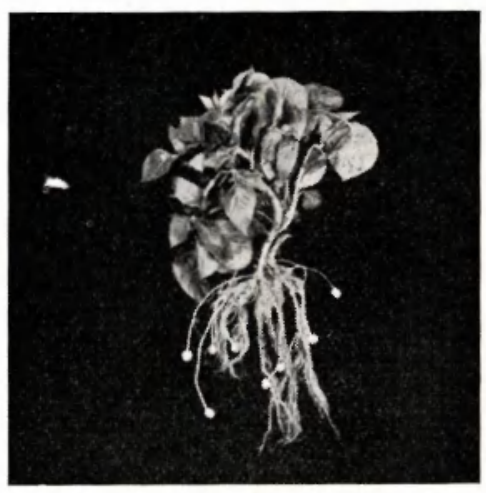

Fig. 13. Bintje 1955 on 31st May, seven WeEks after PLanting. There WERE 32 TUBERS ON THE PLANT, THE LARGEST BELNG 15 MM IN LENGTH.

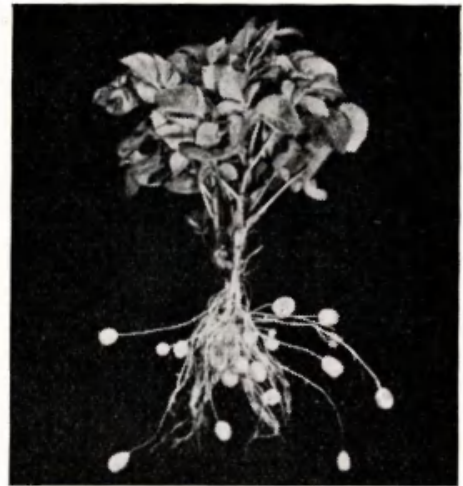

Fig. 14. Bintje 1955 on 6th June. There WERE 40 TUBERS ON THE PLANT, THE LARGEST OF WHTCH WAS 3 CM IN LENGTII.

In connection with the second conclusion, a remark may be quoted which was made by Mr. A. RozeNDAAL when he saw the graphs accompanying this article: "the large tubers grow the quickest, which is why we always find virus in the largest tubers on a plant, and not in the small tubers".

The third conclusion prompts the observation that if a potato variety, or a batch of potatoes which has been subjected to one or other treatment, yields too few tubers on harvesting, this must not be attributed to the fact that the plant did not form a sufficiently large number of tubers, but to the 
fact that too few of the tubers formed grew into usable tubers. We are convinced that it is possible to find a treatment, for application during storage and in the field, for each variety of potato, which would enable an adequate number of tubers to develop properly.

In addition, the following comment may be made on the graphs. Most of them, including those not published, exhibit a break in the lines indicating tuber growth, in the third week in July. This means that tuber growth was at a standstill in this week. As no potatoes were lifted between the middle of June and the middle of July $(1953,1954)$, it is not known whether this suspension of growth did not begin before the middle of July. However, the direction and the degree of the rise in the lines in 1953, 1954 and 1955 clearly indicate that the factor responsible for this stoppage cannot have begun to operate much earlier. No explanation can be given for this phenomenon, but it is sought in two different quarters :

I during the period concerned the potato plants exhibited new growth from the axillary buds of the topmost leaflets on the haulms - "the field turned green again";

II in the third week in July, the critical moment for the potato in the Netherlands arrives, when the store of water in the soil is no longer sufficient for a potato crop, to judge by averages calculated over many years (oral communication from research workers concerned with investigations in connection with climate analysis - Laboratory of Physics and Meteorology, Wageningen, and Royal Netherlands Meteorological Institute, De Bilt).

As a final remark regarding the tuber formation period of two to three weeks, it should be said that we have the impression that the plant is particularly sensitive in this period. By removing a row of plants from the field each week, at both the beginning and end of tuber formation, the advantages of a distance between them and their neighbours which was double the normal distance were made available to the remaining rows of plants. It was found that the plants which were given this double ration of space at commencement of tuber formation (1st June 1954) yielded far more tubers than plants freed in the same manner but fourteen days later. There are three possible explanations for this :

1 more room, at an early stage, has a favourable effect;

2 damage to roots (by removal of adjoining rows) has a much more unfavourable effect on 14th June than on 1st June (greater dryness of the soil ?);

3 the factors named under 1 and 2 work simultaneously.

It is, however, certain that this tuber formation stage is important to the plant. Perhaps it may not be too much even to say that it is this period which decides the size of the harvest, as far as potatoes in the Netherlands are concerned.

INFLUENCE OF TREATMENT (see page 292)

The treatments showed no significant difference as far as tuber formation and growth of the tubers are concerned, provided the sprouts of the seed potatoes were of the same length. 


\section{AbNoRmal Formation of TUBERS}

The foregoing pages relate to what might be called normal formation of tubers. Even concerning this, opinions differ - in the Netherlands, for example. There, the time at which tuber formation takes place is sometimes defined as : date of commencement of flowering. Figs. 9 and 10, however, clearly show that this date is much later than that of tuber formation. But it must be borne in mind that our investigation relates to chitted seed potatoes, whereas the above view relates perhaps to non-chitted seed potatoes; and the latter have not been considered in our inquiry.

In the publication by CLARK (1921) previously referred to, the statement is made: "tuber formation begins, in general, at about the end of the period of flower bud development... f for late varieties when the buds have started to open." This was evidently the case in the U.S.A., in Colorado (Greely) and Maine. Non-chitted seed potatoes were probably used in this American investigation, while it is possible that other influences may also play a part, e.g., differences of soil and climate.

For the rest, it is easy enough to achieve, in addition to normal formation of tubers, tuber formation which can be termed abnormal, either from the point of view of the time at which it takes place, or in other respects.

The literature of the subject mentions a number of possible ways of stimulating the potato plant to fresh tuber formation (Schacht, 1854; Hugo DE VRIEs, 1878 ; Vöchting, 1887).

We shall now name one or two cases which we have observed ourselves :

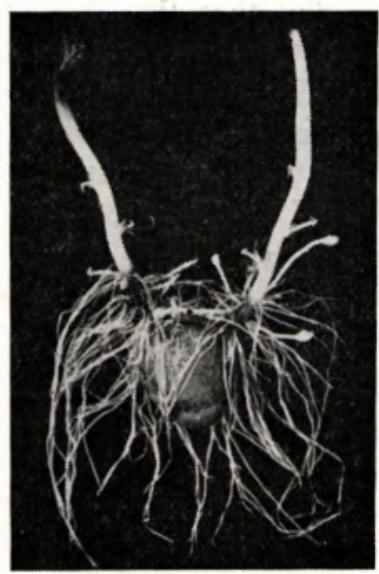

Fig. 15. Eersteling, planted 7 Th April, harvested 22ND April 1942. Seed POTATO STORED FROM IST OCTOBER 1941 AT $13^{\circ} \mathrm{C}$, IN LIGHT (ARTIFICIAL LIGHT, 14 HOURS PER DAY).

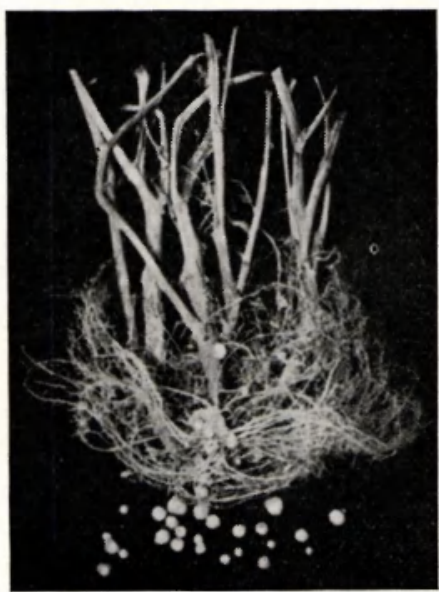

Fig. 16. Voran, Lifted in August 1954, Photographed in OCtober 1954.

1 Fig. 15 shows a plant of the variety Eersteling which had formed tubers as early as $\mathbf{1 5}$ days after being planted in the open field, and which nevertheless hardly projected above the surface of the ground. During these fourteen days the weather was singularly sunny and no frost occurred. In 
January the first sprout was removed, after which the "second" sprouts developed, and the seed was taken for planting.

It must be pointed out that, in this case, not only was the temperature after planting higher than normal, but also the temperature at which the seed potato was stored was much higher than is customary in the Netherlands. In another year, Eersteling seed material was stored in the same way, but the soil after planting was cold (night frost). Here, tubers only began to form after six weeks.

2 Fig. 16 also gives an example of new tuber formation. The plant shown (Voran) is one from which the overground parts of the haulm were cut after lifting, and all tubers, down to the very smallest, the size of a pin's head, were removed. Thereafter, the plant was stored away in a paper bag, at a temperature of $16^{\circ} \mathrm{C}$.

3 A separate phenomenon, or group of phenomena, is that of "second growth", or secondary formation of tubers. This, in our opinion, must be viewed quite independently of normal tuber formation.

Two types of secondary formation of tubers are known:

1 Secondary tuber formation in which only a few eyes of the new tuber continue to grow and form fresh small tubers on top of the first one. Sometimes it is the apical eye which manifest the tendency; but the basal eye may also behave like this (Voran).

The above phenomenon will generally not be regarded as really marking a new period of tuber formation.

2 Secondary tuber formation in which the following grow from the top of the tuber, or from one or two eyes close to the top:

a stolons on which tubers develop, or

b stolons with tubers on the top and on the branch stolons of these stolons, or

c haulms, which form leaves above ground and one or two stolons bearing a tuber underground.

This second mode of secondary tuber formation does therefore amount to a second period of tuber formation.

(In parenthesis, it may be said that types 1 and $2 \mathrm{a}$ are liable to appear somewhere in the Netherlands every year, whereas types $2 b$ and $2 c$ must be regarded as rare occurrences in this country-fortunately, for they occur in a very severe form where they do make their appearance).

The cause of secondary tuber formation may be sought in suspension of growth of tubers owing to unfavourable circumstances, in which drought plays the principle part. This year, however, it has been possible to ascertain that the moisture content of the soil is not the only important factor here, but that the proportion of the quantity of moisture evaporated from the plant to the quantity of moisture assimilated by the roots probably also has a great influence.

In 1955, by removing rows of plants next to the plants which later exhibited secondary tuber growth, evaporation from the surviving plants increased. Simultaneously, assimilation of moisture by the roots decreased, probably owing to the fact that some roots had been damaged by removal of the ad- 
joining rows, while at the same time it was possible for the soil round the plants that were left to lose more moisture through evaporation. It appeared that under these circumstances the secondary tuber formation was stimulated.

\section{BIBLTOGRAPHY}

Clark, C. F.: Development of tubers in the potato. U.S.D.A. Bull. No. 958, 1921.

Krijthe, N. : De invloed van de bewaring der aardappelknollen op de bouw van de knoppen en op de ontwikkeling tot volwassen plant. Lab. of Plant Physiological Research, Wageningen, Comm. 71, 1946.

Sснаснт, H. : Beiträge zur Anatomie und Physiologie der Gewächse, 1854.

SMiтh, O.: Growth and development of the potato as influenced especially by soil reaction. Cornell University Agr. Expt. Sta. Memoir 215, 1938.

Vöchtınc, H. : Ueber die Bildung der Knollen. Bibliotheca Botanica 4, 1887.

VRIES, H. DE : Wachstumgeschichte der Kartoffelpflanze. Landw. Jahrb. 7, 1878. 